\title{
Impact of Title VII Training Programs on Community Health Center Staffing and National Health Service Corps Participation
}

\author{
Diane R. Rittenbouse, $M D, M P H^{1}$ \\ George E. Fryer, Jr, PbD ${ }^{2}$ \\ Robert L. Pbillips, Jr, MD, MSPH \\ Thomas Miyoshi, MSW \\ Christine Nielsen ${ }^{4}$ \\ David C. Goodman, MD, MS \\ Kevin Grumbach, $M D^{1}$ \\ 'Department of Family and Community \\ Medicine and Center for California Health \\ Workforce Studies, University of Califor- \\ nia, San Francisco \\ ${ }^{2}$ Department of Pediatrics, New York Uni- \\ versity School of Medicine, New York \\ ${ }^{3}$ The Robert Graham Center for Policy \\ Studies in Family Medicine and Primary \\ Care, Washington, DC \\ ${ }^{4}$ North Carolina Institute of Medicine, \\ Morrisville \\ ${ }^{5}$ Department of Pediatrics and Center for \\ the Clinical Evaluative Science, Dartmouth \\ Medical School, Hanover, New Hampshire
}

Conflicts of interest: Drs Rittenbouse, Fryer, Pbillips, Miyosbi, Goodman, and Grumbach bold academic appointments in departments that are past or current recipients of Title VII training grants.

\section{CORRESPONDING AUTHOR}

Diane Rittenhouse, MD, MPH Department of Family and Community Medicine and Institute for Health Policy Studies

University of California, San Francisco 500 Parnassus Ave, Room MU 308-E

San Francisco, CA 94143-0900

Rittenhouse@fcm.ucsf.edu

\begin{abstract}
PURPOSE Community health centers (CHCs) are a critical component of the health care safety net. President Bush's recent effort to expand CHC capacity coincides with difficulty recruiting primary care physicians and substantial cuts in federal grant programs designed to prepare and motivate physicians to practice in underserved settings. This article examines the association between physicians' attendance in training programs funded by Health Resources and Services Administration (HRSA) Title VII Section 747 Primary Care Training Grants and 2 outcome variables: work in a $\mathrm{CHC}$ and participation in the National Health Service Corps Loan Repayment Program (NHSC LRP).
\end{abstract}

METHODS We linked the 2004 American Medical Association Physician Masterfile to HRSA Title VII grants files, Medicare claims data, and data from the NHSC. We then conducted retrospective analyses to compare the proportions of physicians working in CHCs among physicians who either had or had not attended Title VII-funded medical schools or residency programs and to determine the association between having attended Title VII-funded residency programs and subsequent NHSC LRP participation.

RESULTS Three percent $(5,934)$ of physicians who had attended Title VII-funded medical schools worked in CHCs in 2001-2003, compared with 1.9\% of physicians who attended medical schools without Title VII funding $(P<.001)$. We found a similar association between Title VII funding during residency and subsequent work in $\mathrm{CHCs}$. These associations remained significant $(P<.001)$ in logistic regression models controlling for NHSC participation, public vs private medical school, residency completion date, and physician sex. A strong association was also found between attending Title VII-funded residency programs and participation in the NHSC LRP, controlling for year completed training, physician sex, and private vs public medical school.

CONCLUSIONS Continued federal support of Title VII training grant programs is consistent with federal efforts to increase participation in the NHSC and improve access to quality health care for underserved populations through expanded CHC capacity.

Ann Fam Med 2008;6:397-405. DOI: 10.1370/afm. 885

\section{INTRODUCTION}

$\mathrm{T}$ The expansion of community health centers (CHCs) is the cornerstone of recent federal efforts to expand access to the underserved. ${ }^{1,2} \mathrm{CHC}$ provide primary care services for underserved populations, including the uninsured, migrant farm workers, and the homeless. In $2005 \mathrm{CHCs}$ provided more than 50 million visits to more than 15 million people, and in recent years CHCs have been a test bed for quality improvement and practice innovation experiments. ${ }^{3-6}$ Although President Bush's Community Health Center Initiative aimed to double the capacity of CHCs between 2002 and 2006, CHCs are struggling to 
recruit sufficient numbers of primary care physicians and have many vacant positions. ${ }^{1,2,7}$

National Health Service Corps (NHSC) physicians make up a substantial proportion of physicians staffing CHCs. ${ }^{7}$ The NHSC Scholarship Program awards full medical school scholarships to students in exchange for a commitment to work in an underserved area after completion of training. The first NHSC scholars began their service in 1977. In 1987 the program was augmented by the establishment of the NHSC Loan Repayment Programs (LRP), offering primary care clinicians payments to be applied against their student loans in return for working in an underserved area. ${ }^{8}$ After completing their NHSC obligation, a large proportion of NHSC participants remain in service to the underserved..$^{9-11}$ Temporary placement of NHSC physicians in rural underserved areas positively affects the long-term nonNHSC physician supply in those areas. ${ }^{12}$ Unfortunately, the demand for NHSC physicians far exceeds the supply. In 2006 there were more than 4,200 vacant positions in underserved areas for NHSC physicians, yet there were only 1,200 NHSC physicians available to fill these slots (personal communication, Health Resources and Services Administration, NHSC Office, April 4, 2006).

Unmet demand for $\mathrm{CHC}$ and NHSC physicians exists in the context of substantial cuts in funding for Health Resources and Services Administration (HRSA) Title VII Section 747 Primary Care Training Grants (Title VII grants)_from \$92.4 million in fiscal year 2003 to $\$ 48.0$ million in $2008 .^{13}$ Title VII grants are intended to strengthen the primary care educational infrastructure at medical schools and residency programs and to encourage physicians-in-training to pursue careers working with underserved populations. ${ }^{14,15}$ Prior research shows an association between Title VII grants to medical schools, an increased production of primary care physicians, ${ }^{16-19}$ and a greater likelihood that graduates will practice in underserved areas. ${ }^{19,20}$ The only published study to examine Title VII grants to residency programs was limited to family physicians in 9 states, which found that family physicians who attended residency programs receiving Title VII grants were more likely than other family physicians to practice in rural and low-income areas. ${ }^{19}$

No prior studies have documented whether obtaining medical training in programs with Title VII grants is associated with subsequent work in CHCs or with participation in the NHSC. We undertook this study to better understand these associations in an effort to inform the federal effort to adequately staff $\mathrm{CHC}$.

\section{METHODS}

We obtained data from the 2004 AMA Physician Masterfile (Masterfile), including Medicare Unique
Physician Identification Numbers (UPINs) for each physician. The Masterfile contains regularly updated information on all US allopathic physicians and many osteopathic physicians. Details on the Masterfile have been published elsewhere. ${ }^{21-23}$

We also obtained data on Title VII grant awards from HRSA's Bureau of Health Professions, including the project director, the awardee institution (medical school, residency program, hospital, university, or other affiliated institution), and type and year of grant. Nine grant types were included and grouped into 3 categories: predoctoral education (predoctoral grants), department development (academic administrative unit or academic unit grants), and residency training (residency grants). Descriptions of the Title VII grant categories are available in the Supplemental Appendix at http://www.annfammed. org/cgi/content/full/6/5/397/DC1.

Between 1972 and 2003, 3,606 predoctoral and academic unit grants were awarded to 137 US medical schools (allopathic and osteopathic). Most grants were to departments of family medicine, because general internal medicine and pediatrics were not eligible until 1998. Using the medical school identifier and state, we linked grants to physician records in the Masterfile, allowing for identification of whether each physician's medical school was receiving Title VII funds during that physician's tenure.

Data on residency grants typically included only an institution and project director. The lack of a common identifier in the AMA Masterfile made matching these grants to programs and, therefore, to physicians, challenging. We matched each recipient institution to a primary care residency program by specialty using FREIDA Online, a database with information on more than 8,200 graduate medical education programs accredited by the Accreditation Council for Graduate Medical Education (ACGME) ${ }^{24}$ Whenever necessary, we conducted hand searches of ACGME historical data and online searches of grantee program directors. Residency programs were characterized as having had a Title VII grant if one of its listed sponsoring or teaching institutions received a residency grant in the primary care specialty (eg, family medicine) of the residency program. There were a total of 6,245 residency grants to 819 residency programs between 1972 and 2003. Using the constructed institution-program link, as well as the institutional identification number in the Masterfile, allowed for identification of whether each physician's residency program was receiving Title VII funds during that physician's tenure.

For analyses, we labeled physicians as having attended a Title VII-funded medical school if their school received a predoctoral grant, an academic unit 
grant, or both during at least one of the years that they attended, and as having attended Title VII-funded residency if their residency program received a residency grant at least 1 year during their tenure.

We used Medicare claims data to identify physicians working in CHCs, using the Centers for Medicaid and Medicare Services outpatient file with a $100 \%$ sample of all beneficiaries who had Medicare outpatient facility claims filed in 2001, 2002, and 2003. Data included the billing physician's UPIN number and whether the claim was for a visit to a Federally Qualified Health Center (FQHC). We used UPIN numbers to link claims files to physician records in the Masterfile. We then classified physicians as working in a CHC for any year 2001-2003 if they billed at least 2 claims from a FQHC in at least 1 of the study years. In this way, we could perform a cross-sectional analysis of physicians who worked in a CHC during the 3-year period, but we did not assess whether a physician ever worked in a $\mathrm{CHC}$.

We obtained the NHSC participant database from the HRSA Bureau of Health Professions, NHSC Division, which contained information on all 13,051 NHSC physician participants between 1975 and 2003. Because a unique physician AMA Medical Education identifier is not one of the data elements in the NHSC participant database, we used a combination of 3 algorithms to match these data to the Masterfile. These algorithms combined last name and first name with (1) exact date of birth, (2) medical school, and (3) graduation year. Masterfile records matched by these protocols produced specificities of $99.9 \%, 98.0 \%$ and $96.0 \%$ respectively. Using this method allowed us to match 11,318 $(86.7 \%)$ of all physicians in the NHSC file to physician entries in the Masterfile. Because some physicians had served in the NHSC as long as 30 years before, at least modest attrition was to be expected.

\section{Data Analyses}

\section{Title VII and Work in CHC}

The proportion of physicians who attended Title VIIfunded medical schools and who worked in a CHC in 2001-2003 was compared with the proportion of physicians who attended non-Title VII-funded schools and who worked in a CHC. Predoctoral education grants, academic unit grants, or both were examined separately. Similar comparisons were made among physicians who attended Title VII-funded and non-Title VII-funded residency programs.

All analyses excluded physicians not active in direct patient care, those still in residency training, and those who completed residency before 1970 (before the inception of the Title VII grants programs). Medical school analyses excluded international and Cana- dian medical graduates, because they could not have attended Title VII-funded medical schools. Residency analyses included international and Canadian medical graduates, but excluded general practitioners and non-primary care physicians because they could not have attended Title VII-funded residency programs, and osteopathic physicians because of the lack of sufficient residency data in the Masterfile. For both medical school and residency analyses, we examined results separately for primary care physicians only (including family physicians, general practitioners, general internists, and general pediatricians), and for family physicians only, because of their distinct funding history. Significance of differences between physicians who attended Title VII-funded, and physicians who attended non-Title VII-funded, training programs was tested using 2-tailed $\chi^{2}$ analyses.

We used logistic regression analysis to examine the independent contribution of each of the 3 types of grants-predoctoral, academic unit, and residencyon working in a $\mathrm{CHC}$. Additional regression models controlled for year of residency completion, public vs private medical school, participation in the NHSC, and physician sex. We hypothesized that more recent graduates were more likely to attend Title VII-funded training programs (because of more grants being awarded in later years) and more likely to work at CHCs (because of service obligations or desire for an underserved practice experience early in their career). Graduates of state-owned medical schools have been shown to be more likely to enter primary care fields. ${ }^{16}$ We controlled for NHSC participation because it is strongly associated with work in a CHC, and trainees willing to participate in the NHSC may also be attracted to training programs that receive Title VII grants to prepare physicians for subsequent work in underserved settings. Only physicians active in direct patient care who graduated from allopathic US medical schools and completed residency training in 1970 or later were included in the regression analyses.

\section{Title VII and NHSC Participation}

Similar methods were used to examine the association between attending Title VII-funded training programs and participation in the NHSC LRP. We included in these analyses all physicians in the Masterfile who completed residency in 1987 or later, based on the start date for the NHSC LRP program. International and Canadian medical graduates were excluded because they are not eligible for NHSC participation. General practitioners, non-primary care physicians, and osteopathic physicians were excluded from residency analyses for the reasons described above.

For all bivariate analyses, significance of differences 
between physicians who attended Title VII-funded programs and those who attended non-Title VIIfunded programs was tested using 2 -tailed $\chi^{2}$ analyses. We performed logistic regression analysis to examine the association between having attended Title VIIfunded programs and participation in the NHSC LRP. The dependent variable was NHSC LRP participation. We hypothesized that attending Title VII-funded medical school and Title VII-funded residency programs would each be associated with NHSC LRP participation, but that the effect of Title VII funding during residency would be stronger given that it is more proximal in time to LRP participation. We therefore included separate independent variables for having attended programs with an academic unit grant, a predoctoral grant, and a residency grant.

Covariates included year completed residency, physician sex, and public vs private medical school. Prior research has shown that graduates of state-owned medical schools are more likely to enter primary care fields. ${ }^{16}$ In addition, tuition differences between public and private schools may affect student debt and thereby influence decisions to participate in the NHSC LRP. The NHSC LRP model was run for primary care physicians only and family physicians only. Inclusion and exclusion criteria for regression analyses were the same as for the bivariate NHSC analyses.

\section{RESULTS}

Descriptive statistics of physicians are displayed in Table 1. The number of physicians for each analysis varies for reasons described in the Methods.

\section{Title VII-Funded Medical Training and Work in CHCs} As shown in Table 2, 3.0\% of physicians who attended Title VII-funded medical schools worked in CHCs in 2001-2003, compared with $1.9 \%$ of physi- cians who attended medical schools that were not Title VII funded $(P<.001)$. Attending a medical school with each type of grant was associated with a greater likelihood of working in a CHC. In analyses limited by specialty, primary care physicians and family physicians/ general practitioners who had attended Title VIIfunded medical schools were also significantly more likely to be working in a CHC. Also shown in Table $2,4.4 \%$ of primary care physicians who had attended
Table 1. Physicians Attending Title VII-Funded Programs, Working in CHCs and Participating in the NHSC LRP, by Specialty

\begin{tabular}{|c|c|c|c|}
\hline Characteristic & $\begin{array}{c}\text { All } \\
\text { Specialties } \\
\text { No. (\%) }\end{array}$ & $\begin{array}{l}\text { PCPs Only } \\
\text { No. (\%) }\end{array}$ & $\begin{array}{l}\text { FPIGPs Only } \\
\text { No. (\%) }\end{array}$ \\
\hline \multicolumn{4}{|l|}{ Analysis of CHC staffing a } \\
\hline Total N for medical school analysis ${ }^{b}$ & 412,012 & 138,197 & 58,299 \\
\hline $\begin{array}{l}\text { Attended Title VII-funded medical } \\
\text { school }\end{array}$ & $201,186(48.8)$ & $78,612(56.9)$ & $36,326(62.3)$ \\
\hline Academic unit grant only & $28,363(6.9)$ & $10,652(7.7)$ & $4,630(7.9)$ \\
\hline Predoctoral grant only & $59,535(14.4)$ & $22,167(16.0)$ & $10,049(17.2)$ \\
\hline Both grants & $113,288(27.5)$ & $45,793(33.1)$ & $21,647(37.1)$ \\
\hline $\begin{array}{l}\text { Attended non-Title VII-funded } \\
\text { medical school }\end{array}$ & $210,826(51.2)$ & $59,585(43.1)$ & $21,973(37.7)$ \\
\hline Worked in CHC (2001-2003) & $9,943(2.4)$ & $5,329(3.9)$ & $3,208(5.5)$ \\
\hline Total $\mathrm{N}$ for residency analysisc & & 173,656 & 59,354 \\
\hline Attended Title VII-funded residency & N/A & $70,529(40.6)$ & $25,098(42.3)$ \\
\hline $\begin{array}{l}\text { Attended non-Title VII-funded } \\
\text { residency }\end{array}$ & N/A & $103,127(59.4)$ & $32,256(57.7)$ \\
\hline Worked in CHC (2001-2003) & N/A & $6,759(3.9)$ & $3,408(5.7)$ \\
\hline \multicolumn{4}{|l|}{ Analysis of NHSC LRP participation ${ }^{d}$} \\
\hline Total N for medical school analysis & 278,975 & 98,390 & 41,275 \\
\hline $\begin{array}{l}\text { Attended Title VII-funded medical } \\
\text { school }\end{array}$ & $192,878(69.1)$ & $73,405(74.6)$ & $32,753(79.4)$ \\
\hline Academic unit grant only & $24,093(8.6)$ & $8,791(8.9)$ & $3,624(8.8)$ \\
\hline Predoctoral grant only & $49,134(17.6)$ & $17,694(18.0)$ & $7,657(18.6)$ \\
\hline Both grants & $119,651(42.9)$ & $46,920(47.7)$ & $21,472(52.0)$ \\
\hline $\begin{array}{l}\text { Attended non-Title VII-funded } \\
\text { medical school }\end{array}$ & $86,097(30.9)$ & $24,985(25.4)$ & $8,522(20.6)$ \\
\hline Participated in NHSC LRP & N/A & $2,017(2.1)$ & $1,272(3.1)$ \\
\hline Total $\mathrm{N}$ for residency analysisc & N/A & 87,591 & 34,224 \\
\hline Attended Title VII-funded residency & N/A & $40,738(46.5)$ & $14,400(42.1)$ \\
\hline $\begin{array}{l}\text { Attended non-Title VII-funded } \\
\text { residency }\end{array}$ & $\mathrm{N} / \mathrm{A}$ & $46,853(53.5)$ & $19,824(57.9)$ \\
\hline Participated in NHSC LRP & N/A & $1,678(1.9)$ & $997(2.9)$ \\
\hline
\end{tabular}

$\mathrm{CHC}=$ community health center; $\mathrm{CMS}=$ Centers for Medicare $\&$ Medicaid Services; FP = family physician; GP $=$ general practitioner; $\mathrm{HRSA}=$ Health Resources and Services Administration; NHSC $=$ National Health Services Corps; LRP = Loan Repayment Program; PCPs = primary care physicians (includes FPs, GPs, general internists, and general pediatricians).

a Includes all US physicians who reported their major professional activity as "direct patient care" and who completed residency in 1970 or later.

b International and Canadian medical school graduates were excluded because they could not have been exposed to Title VII funds during medical school.

' Osteopathic physicians were excluded from residency analyses due to insufficient osteopathic residency data in the AMA Masterfile. General practitioners were excluded from residency analyses because they generally do not undergo full residency training.

${ }^{d}$ Includes all US physicians who completed residency in 1987 or later. International and Canadian medical school graduates were excluded because they are not eligible for the NHSC.

Data source: 2004 AMA Physician Masterfile and HRSA Title VII Training Program grantee database; CMS outpatient claims file, 2001, 2002, 2003; and HRSA Bureau of the Health Professions NHSC participant database. 
Title VII-funded residency programs worked in CHCs in 2001-2003 ompared with 3.5\% of primary care physicians who attended non-Title VII-funded residency programs. Among family physicians attending Title VII-funded residency programs, 6.8\% worked in CHCs compared with $5.0 \%$ of their counterparts who attended non-Title VII-funded programs

Table 3 shows the results of the regression models summarizing the association between physicians attending Title VII-funded programs and working in a CHC. Among all physicians, attending a pro-

Table 2. Number (\%) of Physicians Attending Title VII-Funded Training Programs That Worked in Community Health Centers (20012003) or Ever Participated in the NHSC Loan Repayment Program

\begin{tabular}{|c|c|c|c|}
\hline Characteristic & $\begin{array}{l}\text { All } \\
\text { Specialties } \\
\text { No. }(\%)\end{array}$ & $\begin{array}{l}\text { PCPs Only } \\
\text { No. }(\%)\end{array}$ & $\begin{array}{l}\text { FPIGPs Only } \\
\text { No. (\%) }\end{array}$ \\
\hline \multicolumn{4}{|l|}{ Physicians that worked in $\mathrm{CHCs}^{\mathrm{a}}$} \\
\hline \multicolumn{4}{|l|}{ Medical school analysis ${ }^{b}$} \\
\hline Attended Title VII-funded medical school & $5,934(3.0)^{e}$ & $3,515(4.5)^{e}$ & $2,258(6.2)^{\mathrm{e}}$ \\
\hline Academic unit grant only & $847(3.0)^{e}$ & $506(4.8)^{e}$ & $301(6.5)^{\mathrm{e}}$ \\
\hline Predoctoral grant only & $1,624(2.7)^{\mathrm{e}}$ & $914(4.1)^{\mathrm{e}}$ & $574(5.7)^{\mathrm{e}}$ \\
\hline Both grants & $3,465(3.1)^{\mathrm{e}}$ & $2,095(4.6)^{e}$ & $1,383(6.4)^{\mathrm{e}}$ \\
\hline $\begin{array}{l}\text { Attended non-Title VIl-funded medical } \\
\text { school }\end{array}$ & $4,007(1.9)^{\mathrm{e}}$ & $1,814(3.0)^{\mathrm{e}}$ & $950(4.3)^{\mathrm{e}}$ \\
\hline \multicolumn{4}{|l|}{ Residency analysisc } \\
\hline Attended Title VII-funded residency & $N / A$ & $3,130(4.4)^{\mathrm{e}}$ & $1,698(6.8)^{\mathrm{e}}$ \\
\hline Attended non-Title VII-funded residency & $N / A$ & $3,629(3.5)^{\mathrm{e}}$ & $1,710(5.0)^{\mathrm{e}}$ \\
\hline \multicolumn{4}{|l|}{ Physicians that participated in NHSC LRPd } \\
\hline \multicolumn{4}{|l|}{ Medical school analysis } \\
\hline Attended Title VII-funded medical school & $1,828(0.9)^{\mathrm{e}}$ & $1,508(2.1)$ & $1,011(3.1)$ \\
\hline Academic unit grant only & $204(0.8)$ & $169(1.9)$ & $99(2.7)$ \\
\hline Predoctoral grant only & $494(1.0)^{\mathrm{e}}$ & $413(2.3)^{f}$ & $292(3.8)^{\mathrm{g}}$ \\
\hline Both grants & $1,130(0.9$ e & $926(2.0)$ & $620(2.9)$ \\
\hline $\begin{array}{l}\text { Attended non-Title VII-funded medical } \\
\text { school }\end{array}$ & $626(0.7)$ & $509(2.0)$ & $261(3.1)$ \\
\hline \multicolumn{4}{|l|}{ Residency analysisc } \\
\hline Attended Title VII-funded residency & $\mathrm{N} / \mathrm{A}$ & $891(2.2)^{\mathrm{e}}$ & $524(3.6)^{e}$ \\
\hline Attended non-Title VII-funded residency & $\mathrm{N} / \mathrm{A}$ & $787(1.7)$ & $473(2.4)$ \\
\hline \multicolumn{4}{|c|}{$\begin{array}{l}\mathrm{CHC}=\text { community health center; } \mathrm{CMS}=\text { Centers for Medicare and Medicaid Services; } \mathrm{FP}=\text { family physician; } \\
\mathrm{GP}=\text { general practitioner; } \mathrm{NHSC}=\text { National Health Service Corps; HRSA = Health Resources and Services } \\
\text { Administration; } \mathrm{LRP}=\text { Loan Repayment Program; } \mathrm{PCPS}=\text { primary care physicians (includes FPs, GPs, general } \\
\text { internists, and general pediatricians). }\end{array}$} \\
\hline \multicolumn{4}{|c|}{$\begin{array}{l}\text { a Includes all US physicians who reported their major professional activity as "direct patient care" and who } \\
\text { completed residency in } 1970 \text { or later. }\end{array}$} \\
\hline \multicolumn{4}{|c|}{$\begin{array}{l}\text { b International and Canadian medical school graduates excluded because they could not be exposed to Title VI } \\
\text { during medical school. }\end{array}$} \\
\hline \multirow{2}{*}{\multicolumn{4}{|c|}{$\begin{array}{l}\text { ' GPs and osteopathic physicians excluded from residency analyses because GPs generally do not undergo full } \\
\text { residency training, and because there are insufficient osteopathic residency data in the AMA Masterfile. } \\
\text { d Includes all US physicians who completed residency in } 1987 \text { or later. International and Canadian medical } \\
\text { school graduates were excluded because they are not eligible for the NHSC LRP. }\end{array}$}} \\
\hline & & & \\
\hline \multirow{2}{*}{\multicolumn{4}{|c|}{$\begin{array}{l}\text { e Significant at } P<.001 \text { for comparisons between physicians who attended Title VII-funded programs and phy- } \\
\text { sicians who attended non-Title VII-funded programs, using } \chi^{2} \text { tests. } \\
\text { 'Significant at } P<.05 \text { for comparisons between physicians who attended Title VII-funded programs and physi- } \\
\text { cians who attended non-vTitle VII-funded programs, using } \chi^{2} \text { tests. }\end{array}$}} \\
\hline & & & \\
\hline \multicolumn{4}{|c|}{$\begin{array}{l}{ }^{g} \text { Significant at } P<.01 \text { for comparisons between physicians who attended Title VII-funded programs and physi- } \\
\text { cians who attended non-Title VII-funded programs, using } \chi^{2} \text { tests. }\end{array}$} \\
\hline \multicolumn{4}{|c|}{$\begin{array}{l}\text { Data source: } 2004 \text { AMA Physician Masterfile; HRSA Title VII Training Program grantee database; CMS outpa- } \\
\text { tient claims file, 2001, 2002, 2003; and HRSA Bureau of the Health Professions NHSC participant database. }\end{array}$} \\
\hline
\end{tabular}

gram with a Title VII predoctoral grant (odds ratio $[\mathrm{OR}]=1.25 ; 95 \%$ confidence interval $[\mathrm{CI}], 1.19-1.32)$, an academic unit grant $(\mathrm{OR}=1.28 ; 95 \% \mathrm{CI}, 1.22-1.35)$, and a residency grant $(\mathrm{OR}=1.16 ; 95 \% \mathrm{CI}, 1.11-1.20)$ were each independently and significantly associated with working in a CHC. Not surprisingly, the odds ratios for the associations between attending a Title VII-funded residency program and working in a $\mathrm{CHC}$ were greater when limited to primary care physicians and family physicians, since the effect of the residency training grant exposure is diluted in analyses that include non-primary care physicians who subspecialized after generalist training or who trained in programs that would not have been eligible for Title VII grants. In regression models that included additional covariates, attending programs with Title VII academic unit and residency grants remained significantly and positively associated with working in a CHC (Table 3). Attending medical schools with Title VII predoctoral grants was no longer significant in the all physician and primary care physician models, however, and had a significant, negative association in the model for family physicians. NHSC participation had a strong, positive association with working in a $\mathrm{CHC}$.

\section{Title VII-Funded Medical Training and NHSC LRP Participation}

As shown in Table 2, the percentage of physicians participating in the LRP was $0.9 \%$ among physicians attending Title VII-funded medical schools, and $0.7 \%$ among physicians who attended non-Title VII-funded schools $(P<.001)$. The proportion of family physicians and general practitioners who participated in the LRP was the same $(3.1 \%)$ among those who attended Title VII-funded medical schools and those who did not, although $3.8 \%$ of family physicians and general practitioners attending a medical school with a pred- 


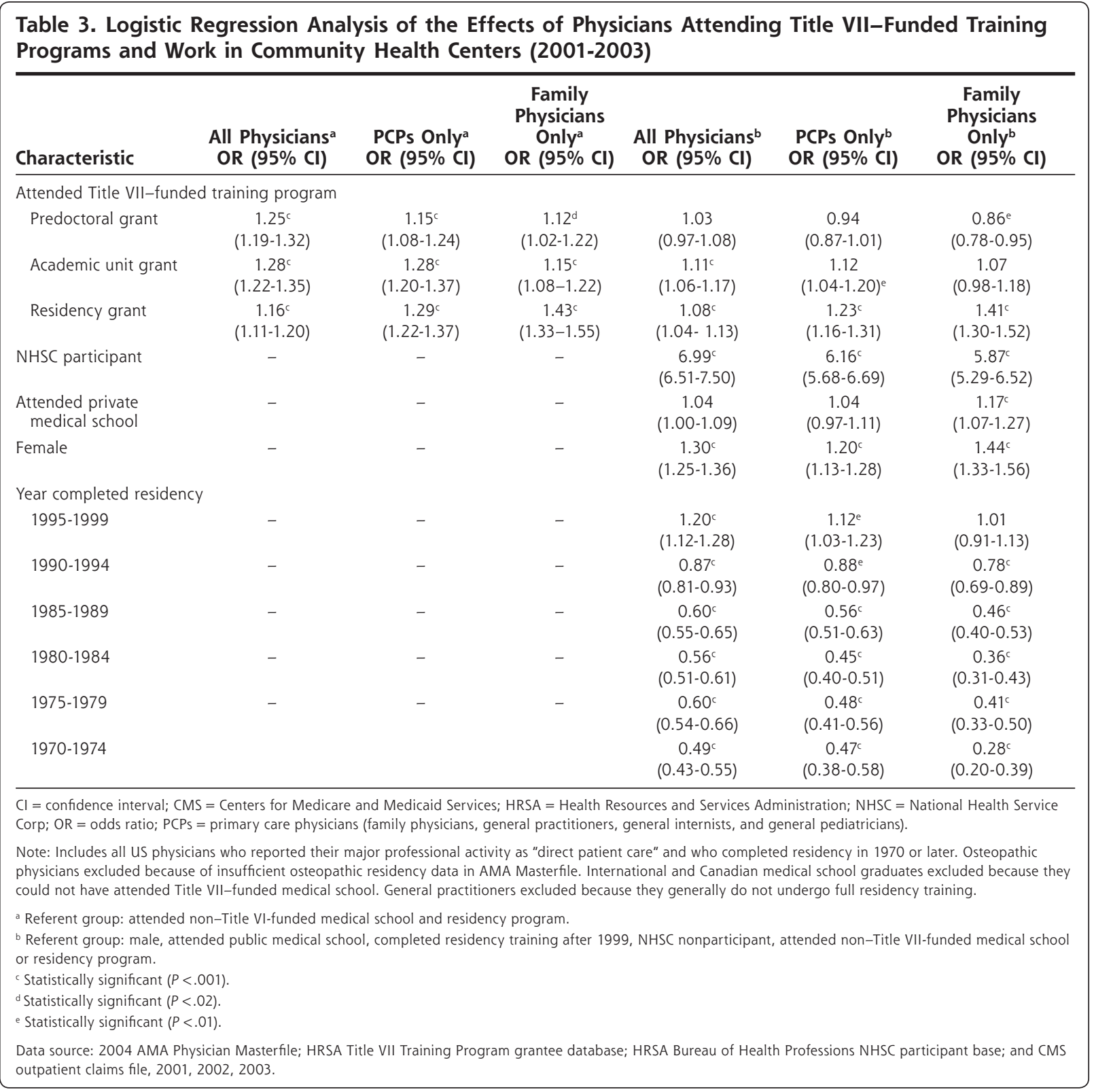

octoral grant subsequently participated in the NHSC LRP $(P<.01)$. Among primary care physicians attending Title VII-funded residency programs, the proportion who participated in the NHSC LRP was $2.2 \%$, compared with $1.7 \%$ among other primary care physicians $(P<.001) ; 3.6 \%$ of family physicians who attended Title VII-funded residency programs were LRP participants, compared with only $2.4 \%$ who attended non-Title VIIfunded programs $(P<.001)$.

Table 4 displays the results of the logistic regression analysis for participation in the NHSC LRP. Among primary care physicians, attending a Title VII-funded medical school with a predoctoral grant, but not an academic unit grant, was positively associ- ated with NHSC LRP participation. Attending a Title VII-funded residency program $(\mathrm{OR}=1.27$; 95\% CI, $1.15-1.40)$ was also positively and significantly associated with NHSC LRP participation. The strong association between LRP participation and having attended Title VII-funded residency programs, relative to attending medical schools with predoctoral or academic unit grants, may be explained by the distance between medical school and the decision to participate in the LRP (usually during or after residency). In the family physician-only analysis, having attended a Title VII-funded residency program was strongly associated with NHSC LRP participation $(\mathrm{OR}=1.56$; 95\% CI, 1.37-1.77). Attending a medical school with a Title VII 
predoctoral grant had a positive, but not statistically significant, coefficient in the model. Attending a medical school with an academic unit grant was negatively associated with participation in the $\operatorname{LRP}(\mathrm{OR}=0.85$; 95\% CI, 0.73-0.98).

\section{DISCUSSION}

We found a strong association between attending Title VII-funded medical training programs and 2 important outcome variables: (1) practice in CHCs, and (2) participation in the NHSC LRP. In regression models controlling for other factors, attending Title VII-funded medical schools and residency programs were independently associated with participation in the NHSC LRP, as well as independently associated with working in a $\mathrm{CHC}$, even when controlling for NHSC participation, an important pathway to practice in underserved settings. This study is the first to examine the Title VII grants program in such a comprehensive manner by using the AMA Masterfile enhanced through analytic linkages with multiple other data sources, including Medicare claims data.

Our findings are consistent with previous research on Title VII funding, specialty choice, and practice

\begin{tabular}{|c|c|c|}
\hline Characteristic & $\begin{array}{c}\text { PCPs Only } \\
n=87,558 \\
\text { OR }(95 \% \text { Cl) }\end{array}$ & $\begin{array}{c}\text { Family Physicians Only } \\
n=34,212 \\
\text { OR }(95 \% \mathrm{Cl})\end{array}$ \\
\hline \multicolumn{3}{|l|}{$\begin{array}{l}\text { Attended Title VII-funded } \\
\text { training programs }\end{array}$} \\
\hline Academic unit grant & $0.96(0.86-1.08)$ & $0.85(0.73-0.98)^{\mathrm{a}}$ \\
\hline Predoctoral grant & $1.15(1.02-1.30)^{a}$ & $1.17(0.99-1.38)$ \\
\hline Residency grant & $1.27(1.15-1.40)^{\mathrm{b}}$ & $1.56(1.37-1.77)^{\mathrm{b}}$ \\
\hline Attended private medical school & $1.41(1.27-1.57)^{b}$ & $1.60(1.39-1.83)^{b}$ \\
\hline Female & $0.91(0.83-1.00)$ & $0.80(0.70-0.91)^{c}$ \\
\hline \multicolumn{3}{|l|}{ Year completed residency } \\
\hline 1995-1999 & $1.42(1.24-1.63)^{\mathrm{b}}$ & $1.38(1.17-1.63)^{\mathrm{b}}$ \\
\hline 1990-1994 & $1.72(1.50-1.97)^{\mathrm{b}}$ & $1.32(1.10-1.58)^{c}$ \\
\hline 1985-1989 & $0.74(0.61-0.90)^{c}$ & $0.57(0.44-0.74)^{b}$ \\
\hline
\end{tabular}

$\mathrm{Cl}=$ confidence interval; $\mathrm{HRSA}=$ Health Resources and Services Administration; NHSC = National Health Service Corps; OR = odds ratio; $\mathrm{PCPs}=$ primary care physicians (family physicians, general practitioners, general internists, and general pediatricians).

Note: Includes all us physicians who completed residency in 1987 or later. International and Canadian medical school graduates excluded because they are not eligible for NHSC participation. Osteopathic physicians excluded because of insufficient osteopathic residency data in the AMA Masterfile. General practitioners excluded because they generally do not undergo full residency training.

Referent group: male, attended public medical school, completed residency after 1999, attended non-Title VIIfunded medical school and residency program.

a Statistically significant $(P<.03)$.

b Statistically significant $(P<.001)$.

' Statistically significant $(P<.01)$.

Data source: 2004 AMA Physician Masterfile; HRSA Title VII Training Program grantee database; and HRSA Bureau of the Health Professions NHSC participant database. in underserved communities. ${ }^{19,20}$ This study adds to the specificity of the association of these grants, both to when medical trainees are exposed and to where they wind up practicing. That the effects of attending schools with predoctoral and academic unit grants show a weaker association with outcome variables in regression models limited to primary care physicians or family physicians should be considered in the context of earlier research showing that greater proportions students exposed to Title VII grants during medischool pursue primary care specialties, especially ly medicine, and practice in rural areas. ${ }^{16-20}$ Charzing predoctoral grant effects as insignificant bitory would be incorrect. Rather, the positive setween medical school grants and our be moderated in the analyses limited to primary care physicians and/or family physicians by the choice of residency-eg, more graduates from Title VII-funded schools enter primary care and family medicinerather than medical school grants selectively influencing practice choices among the graduates entering these specialties. Our findings suggest that once physicians have made the decision to enter into primary care and family medicine residency programs, they are more strongly influenced in their practice decisions by exposure to Title VII residency grants.

Our study has several limitations. First, the observational nature of the study design limits the ability to make causal inferences. Although we controlled for several possible confounding variables, it is possible that attending medical schools and residency programs with Title VII funding is correlated with some unmeasured characteristics of physicians or their training environments. Moreover, it is possible that causation works in the opposite direction. For example, medical schools and residency programs with a large proportion of their graduates working in underserved settings receive additional points in the HRSA grant-review-scoring system, so these schools and programs may be more likely to receive Title VII grants as a result of having many graduates working in CHCs. We attempted to address these issues of reverse 
causality by using only current practice at a $\mathrm{CHC}$ as the outcome variable, for example, and retrospectively measuring whether individual physicians had attended Title VII-funded medical schools and residency programs. Including NHSC scholarship participation in the NHSC control variable in the regression models predicting $\mathrm{CHC}$ participation may also serve as a proxy for measuring physicians' underlying predisposition to work at a CHC, insofar as NHSC scholarship participants have committed to this career pathway at medical school matriculation and before exposure to Title VII-supported activities. Also, the Title VII grant-funding history for most institutions allows for a form of pre-post analysis at the institution level, as once an institution received a Title VII grant it was unlikely to lose the funding in subsequent years. The great majority of physicians in our group attending non-Title VII-funded medical training programs therefore attended a medical school or residency program that either never received a Title VII grant or had not yet received a Title VII grant.

Another limitation is the use of Medicare claims data to identify physicians working in CHCs. Although accurate, this method may be susceptible to false-negative bias, because some physicians working in $\mathrm{CHCs}$ (eg, pediatricians) may not be identified using Medicare claims. Undercounting physicians working in $\mathrm{CHCs}$ should not bias the association between attending Title VII-funded programs and subsequent $\mathrm{CHC}$ practice.

Our findings represent conservative estimates of the number of physicians staffing CHCs and similar safety net clinics. We measured physician practice at a CHC during only a 3-year period and focused on federally designated $\mathrm{CHCs}_{\text {; }}$ other types of safety net clinics (state- and county-sponsored clinics, free clinics, etc), were not considered. Previous studies suggest that including service at CHCs in earlier years and counting physicians working in non-CHC safety net clinics would produce higher overall estimates of Title VII exposure and safety net clinic practice. ${ }^{19,20}$ Similarly, our NHSC LRP participation outcome variable does not consider participation in the large number of state-run loan-forgiveness and related programs that provide financial support in exchange for physicians' service in defined underserved areas. We would expect training in Title VII-funded schools and residency programs to be similarly associated with participation in these state-run programs.

In summary, our findings provide evidence that the Title VII Section 747 grant program supports the training of physicians who are more likely to staff CHCs and participate in the NHSC LRP. These findings have important implications for federal policy decisions, including the recent major reduction in
Title VII Section 747 funding. Reductions in Title VII destabilize institutions that disproportionately serve as the pipeline for producing physicians who participate in the NHSC and/or work at CHCs, potentially undermining the federal effort to improve access for the underserved through CHC expansion. Ongoing federal investment in the medical education pipeline to prepare and motivate physicians to participate in the NHSC and to work in CHCs should be considered an integral component of efforts to improve access to care for the underserved.

To read or post commentaries in response to this article, see it online at http://www.annfammed.org/cgi/content/full/6/5/397.

Key words: Title VII training programs; community health centers; National Health Service Corps; medically underserved area/manpower; education, medical; health policy research; primary health care

Submitted November 1, 2007; submitted, revised, June 4, 2008; accepted June 24, 2008.

This work was presented at the AcademyHealth 2007 Annual Research Meeting, Orlando, Florida; at the Third Annual AAMC Physician Workforce Research Conference, Bethesda, Maryland; and at the Robert Wood Johnson Foundation Generalist Physician Faculty Scholars 2005 Annual Meeting, Ponte Vedra Beach, Florida.

Funding support: Prepared under contract No. HHSH 230200432035 C by the University of California, San Francisco for the Evaluation and Analysis Branch, Office of Workforce Evaluation and Quality Assurance, Bureau of Health Professions, HRSA.

Acknowledgments: We greatly appreciate the research assistance of Edward Bender at the University of Rochester and the administrative support of Linda Eng at UCSF and Angela Kalish at the University of Rochester.

\section{References}

1. O'Malley AS, Forrest CB, Politzer RM, Wulu JT, Shi L. Health center trends, 1994-2001: what do they portend for the federal growth initiative? Health Aff. 2005;24(2):465-472.

2. Iglehart JK. Spreading the safety net-obstacles to the expansion of community health centers. N Engl J Med. 2008;358(13):1321-1323.

3. Proser M, Shin P, Hawkins D. A Nation's Health at Risk III: Growing Uninsured, Budget Cutbacks Challenge President's Initiative to Put a Health Center in Every Poor County. Washington, DC: National Association of Community Health Centers and The George Washington University; 2005.

4. Landon BE, Hicks LS, O'Malley AJ, et al. Improving the management of chronic disease at community health centers. $N$ Engl J Med. 2007;356(9):921-934.

5. Health Disparities Collaboratives. Improving Diabetes Care in 3,400 Health Center Sites. http://www.ihi.org/lHI/Topics/Improvement/SpreadingChanges/ImprovementStories/HealthDisparitiesCollaboratives.htm. Institute for Healthcare Improvement. Accessed Aug 18, 2008.

6. Health care foundations announce $\$ 4.5$ million program to speed adoption of electronic health records in community clinics. http:// www.chcf.org/press/view.cfm?itemid=121207. California Healthcare Foundation, May 2006. Accessed Aug 18, 2008. 
7. Rosenblatt RA, Andrilla CH, Curtin T, Hart LG. Shortages of medical personnel at community health centers: implications for planned expansion. JAMA. 2006;295(9):1042-1049.

8. Fryer GE, McCann JL, Dodoo MS, et al. Access, health, and wealth: the impact of the National Health Service Corps in rural America, 1970-2000. http://www.grahamcenter.org/PreBuilt/nhsc.pdf. Accessed Aug 18, 2008.

9. Porterfield DS, Konrad TR, Porter CQ, et al. Caring for the underserved: current practice of alumni of the National Health Service Corps. J Health Care Poor Underserved. 2003;14(2):256-271.

10. Rosenblatt RA, Saunders G, Shreffler J, Piriani MJ, Larson EH, Gart GL. Beyond retention: National Health Service Corps participation and subsequent practice locations of a cohort of rural family physicians. J Am Board Fam Pract. 1996;9(1):23-30.

11. Cullen TJ, Hart G, Whitcomb ME, Rosenblatt RA. The National Health Service Corps: rural physician service and retention. J Am Board Fam Pract. 1997;10(4):272-279.

12. Pathman DE, Fryer GE Jr, Phillips RL, Smucny J, Miyoshi T, Green LA. National Health Service Corps staffing and the growth of the local rural non-NHSC primary care physician workforce. J Rural Health. 2006;22(4):285-293.

13. US Department of Health and Human Services. Health Resources and Services Administration Web site. http://www.hrsa.gov/about/ budgetjustification09/hptraining.htm. Accessed Aug 18, 2008.

14. Council on Graduate Medical Education. Financing Graduate Medical Education in a Changing Health Care Environment. Fifteenth Report. Rockville, MD: Bureau of Health Professions, Health Resources and Services Administration; 2000.

15. Mullan F. Where does it hurt, doc? Where they cut out the training. The Washington Post. 2002;Aug 18; Sect. B.03.
16. Rosenblatt RA, Whitcomb ME, Cullen TJ, Lishner DM, Hart LG. The effect of federal grants on medical schools' production of primary care physicians. Am J Public Health. 1993;83(3):322-328.

17. Alpert JJ, Bauchner H, Pelton SI, Siegel B, Levenson S, Vinci R. Career choice in one general pediatric Title VII-supported residency. Arch Pediatr Adolesc Med. 1995;149(9):1019-1021.

18. Politzer RM, Horab S, Fermandez E, Gamliel S, Kahn N, Mullan F. The impact of Title VII departmental and predoctoral support on the production of generalist physicians in private medical schools. Arch Fam Med. 1997;6(6):531-535.

19. Fryer GE Jr, Meyers DS, Krol DM, et al. The association of Title VII funding to departments of family medicine with choice of physician specialty and practice location. Fam Med. 2002;34(6):436-440.

20. Krist AH, Johnson RE, Callahan D, Woolf SH, Marsland D. Title VII funding and physician practice in rural or low-income areas. J Rural Health. 2005;21(1):3-11

21. Pasko T, Seidman B, Birkhead S. Physician Characteristics and Distribution in the US, 2000-2001. Chicago, IL: American Medical Association; 2000.

22. Kletke PR, Polsky D, Wozniak GD, Escarce JJ. The effect of HMO penetration on physician retirement. Health Serv Res. 2000;35(5): 17-31.

23. Baldwin LM, Adamache W, Klabunde CN, Kenward K, Dahlman C, Warren JL. Linking physician characteristics and Medicare claims data: issues in data availability, quality, and measurement. Med Care. 2002;40(8)(suppl):iv82-iv95.

24. Online FREIDA. Fellowship and Residency Electronic Interactive Database. http://www.ama-assn.org/ama/pub/category/2997.html. American Medical Association, 2006. Accessed Aug 18, 2008. 